\title{
Prevalence of Substance Abusers in a Tourist Area
}

\author{
Sunil Kumar ${ }^{1}$, Neelam Kotwal ${ }^{2}$, Monika Malhotra ${ }^{1}$ and Mohammad Sarwar Mir ${ }^{3}$ \\ ${ }^{1}$ MO Grade 1 ESIC Hospital Jammu. India \\ ${ }^{2}$ Former Medical Officer at Shri Mata Vaishno Devi Shrine Board, Jammu, India \\ ${ }^{3}$ Senior Resident, SKIMS, Soura, India
}

Submission: January 17, 2019; Published: April 09, 2019

*Corresponding author: Sunil Kumar, MO Grade 1 ESIC Hospital Jammu. India

\begin{abstract}
Introduction: Substance abuse is a global problem in the youth which is becoming a catastrophe and it is more prevelant in tourist areas worldwide.
\end{abstract}

Material and Methods: This was a cross sectional study held during the month of January 2015 at health camps organized in a tourist area by HR foundation. A Total 2000 subjects were studied, out of which 200 were drug addicts .

Results and conclusion: A prevalence rate of ten percent was obtained. It was observed that males were commonly involved. The victims belonged to younger age groups and lower socioeconomic section. The most commonly abused substance was Charas.

Keywords: Drug abuse; Abuse; Tourist

\section{Introduction}

The drug abuse is the complex problem of not only of individual but also of the entire community [1]. According to the World Health Organization (WHO) substance use is persistent or sporadic drug inconsistent with or unrelated to acceptable medical practices [2]. A drug is broadly defined as any chemical agent that affects living protoplasm. Some drugs reinforcement i.e. they produce the effects that user enjoy and which make him/her wish to take it again or to induce drug seeking behavior $[3,4]$. The substance is common in tourist areas worldwide. The study aimed to find out prevalence of substance abuse in a tourist area of Srinagar.

\section{Material and Methods}

This was a cross sectional study held during the month of January 2015 at health camps organized in a tourist area by HR foundation. The subject were examined by group of medical experts and were labeled as drug dependent based on history, clinical examination, signs and symptoms, and features of withdrawal syndrome. Data was collected by using a standardized proforma. Data was entered in MS Excel and analyzed by SPSS 2.0 version.

Results

A total of 2000 residents participated in the study out of which 200 turned out to be substance abusers yielding a prevalence of $10 \%$ (Figures 1-5).

\section{prevalence of substance abuse $(n=2000)$}

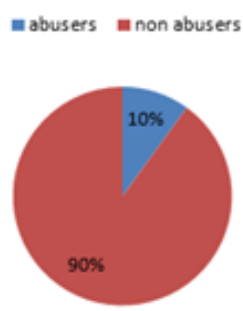

Figure 1: Prevalence of substance abuse.

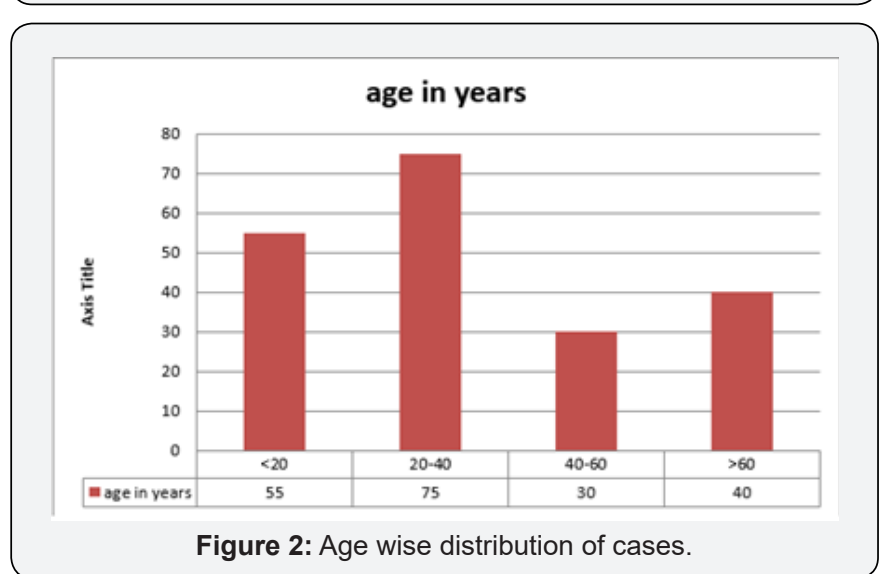

Discussion

Substance abuse is a global problem in the youth which is becoming a catastrophe and it is more prevalent in tourist areas 
worldwide. The substance is common in tourist areas worldwide. The study aimed to find out prevalence of substance abuse in a tourist area of Srinagar. According to the World Health Organization (WHO) substance use is persistent or sporadic drug inconsistent with or unrelated to acceptable medical practices.

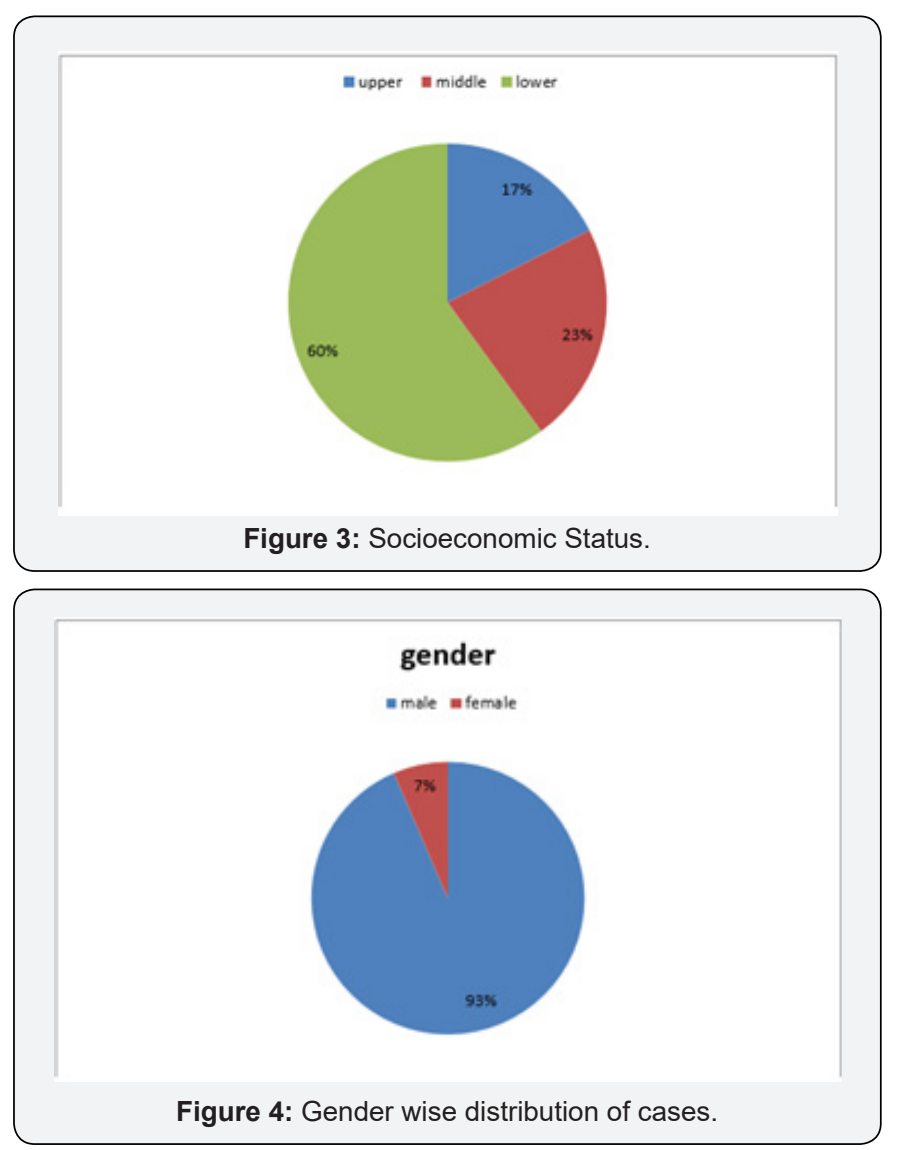

The study yielded a prevalence ten percent in a tourist area of Srinagar. The majority of subjects were males and below 40 years of age. The results are consistent with other studies which also showed that younger males were commonly involved in drug abuse $[1,5,6]$. The facts are disturbing as disturbing as the most productive section of society is involved in drug abuse which can have disastrous consequences on growth of the nation. Charas was the most commonly abused substance followed by alcohol as found in other study also [4].

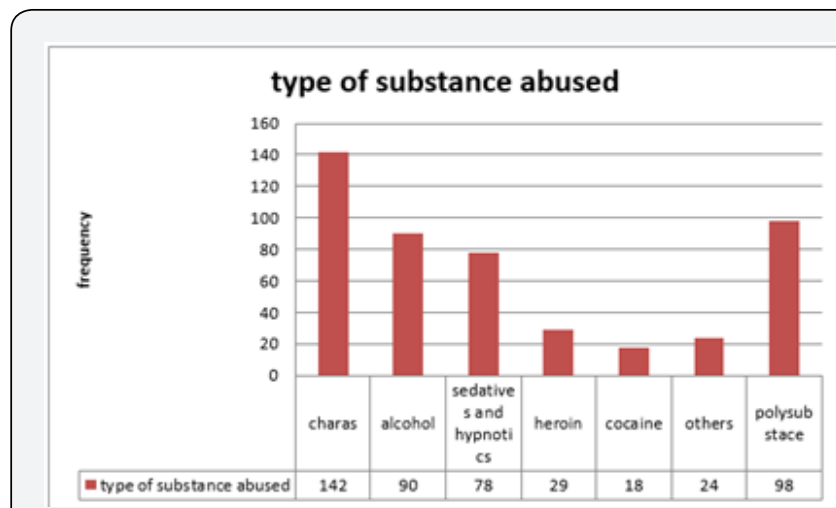

Figure 5: Distribution of cases according to substance abused.

\section{Conclusion}

The total prevalence of substance abuse was found to be 10 percent. Majority of the victims were younger males belonging to lower socioeconomic order [7].

\section{References}

1. Jumade PP, Kasbe AM, Giri PA (2016) Socio-demographic profile of male drug abusers residing in Mumbai city, Maharashtra, India. Int J Community ed Public Health 3: 1115-8.

2. WHO (1999) Techn, Res, Ser 886: 48.

3. Goodman, Gilman's (2011) The Pharmacological Basis of Therapeutics, $12^{\text {th }}$ ed. Chapter 1, Drug Invention and the Pharmaceutical Industry.

4. Neelam Kotwal, Sunil Kumar, Monika Malhotra, Amit Thakur, Mohammad Sarwar Mir (2018) Profile and Pattern of substance abuse: Substance abuse a global problem. CTBEB 18(2): 01-03.

5. Kumar V, Nehra DK, Kumar P, Sunila, Gupta R (2013) Profile of Drug Abuse: A study from Deaddiction Centre; State Institute of Mental Health, Rohtak, Delhi Psychiatry Journal 16(1): 15-23.

6. Manick, Singh M (2013) Drug addiction in Punjab: an empirical study of a village. Political Economy Journal of India.

7. Mayo Clinic Diseases and Condition: Drug Addiction.

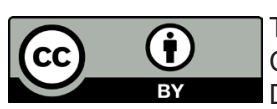

This work is licensed under Creative Commons Attribution 4.0 License DOI: 10.19080/CTBEB.2019.19.556001 